\title{
Solid and papillary epithelial neoplasm arising in heterotopic pancreatic tissue of the mesocolon
}

T Tornóczky, E Kálmán, P Jáksó, G Méhes, L Pajor, G G Kajtár, I Battyány, S Davidovics, M Sohail, T Krausz

Department of Pathology, University Medical School of Pécs, Szigeti út 12., H-7643, Hungary

T Tornóczky

E Kálmán

P Jáksó

G Méhes

L Pajor

Oncohaematology Division of Department of Pediatrics, University Medical School of Pécs G G Kajtár

Department of Pediatric Surgery, University Medical School of Pécs

I Battyány

Department of Radiology, University Medical School of Pécs $S$ Davidovics

Department of Histopathology, Imperial College of Science, Technology and Medicine, Hammersmith Hospital, London M Sohail

Department of Pathology, Laboratory of Surgical Pathology, University of Chicago Hospital, 5841 South Maryland Avenue MC6101, Chicago, IL 60637, USA

$\mathrm{T}$ Krausz

Correspondence to: Dr T Tornóczky yst@pathology.pote.hu

Accepted for publication 28 June 2000

\section{Abstract}

Aim-Solid and papillary epithelial neoplasm (SPEN) is an uncommon pancreatic tumour. Very rarely it has also been described outside the pancreas, usually arising from heterotopic pancreatic tissue. This report summarises all the published extrapancreatic SPENs and documents the sixth such case arising from heterotopic pancreatic tissue of the transverse mesocolon in a 15 year old girl. Methods/Results-Histological and immunohistochemical examination revealed typical papillary and solid areas composed of columnar, cuboidal, and round cells, which were focally positive for vimentin, cytokeratin, neurone specific enolase, carcinoembryonic antigen, a1antitrypsin, $\alpha 1$-antichymotrypsin, and negative for neuroendocrine markers (neurofilament, PGP 9.5, chromogranin A, synaptophysin, and S100), p53, and oestrogen and progesterone receptors. Electron microscopy showed scant zymogen but no neurosecretory granules. In agreement with the flow cytometric result of diploidy, comparative genomic hybridisation (CGH) did not reveal loss or gain of genetic material, and the in situ hybridisation analysis of the RB1 and p53 genes revealed no abnormality in the $13 q$ and $17 p$ arms.

Conclusions-Immunohistochemical and electron microscopic data support exocrine differentiation. The CGH and the flow cytometric results suggest a subtle, yet unknown genetic change, rather than a large genetic alteration. $\mathrm{RB} 1$ and p53 in situ hybridisation ruled out the role of deletion at these sites in the pathogenesis of SPEN. Interestingly, review of the published and the present heterotopic pancreatic SPENs identified the mesocolon as the most common anatomical site (four of six), despite the very rare occurrence of ectopic pancreatic tissue at this site. (F Clin Pathol 2001;54:241-246)

Keywords: solid papillary epithelial neoplasm; heterotopic/ectopic pancreas; mesocolon

Solid and papillary epithelial neoplasm (SPEN) is a rare tumour in the pancreas. Although more than 300 cases have been reported in the pancreas, the occurrence of SPEN at a heterotopic site is not well recognised. Our literature review identified only five previously published cases. ${ }^{1-5}$ The histological diagnosis of SPEN is often difficult, even more so when it occurs at an ectopic site. The histogenesis is still poorly understood and the molecular pathological data are limited. ${ }^{6}$

A 15 year old girl was admitted to the department of paediatrics, University Medical School of Pécs, Hungary, with a history of abdominal pain of recent onset and abdominal distention of several years duration. On physical examination, a large tumour filling the left hypochondrium was identified. On the computed tomography (CT) scan a hypodense, intraperitoneal, circumscribed mass dislocating the spleen and left kidney was observed (fig 1). On laparotomy, a spherical, encapsulated tumour mass was located in the mesocolon. The tumour was not attached to the pancreas and did not appear to invade the colonic wall. It was resected with a segment of transverse colon.

The surgical specimen consisted of a circumscribed mesocolonic tumour mass with an attached $200 \mathrm{~mm}$ length of normal transverse colon. The tumour weighed $2500 \mathrm{~g}$ and measured $210 \mathrm{~mm}$ in the largest diameter. It was easily separable from the colonic wall. The cut surface revealed an encapsulated neoplasm with cystic changes, large areas of necrosis and haemorrhage.

In addition to routine and immunohistochemical staining, electron microscopy, flow cytometry, fluorescent in situ hybridisation (FISH) on tumour imprints, and comparative genomic hybridisation ( $\mathrm{GCH})$ were also performed to characterise the immunophenotype and ultrastructure, the ploidy, the p53 (17p13.1, biotin labelled; Oncor, Gaithersburg, USA), and the RB1 (13q14.2, biotin

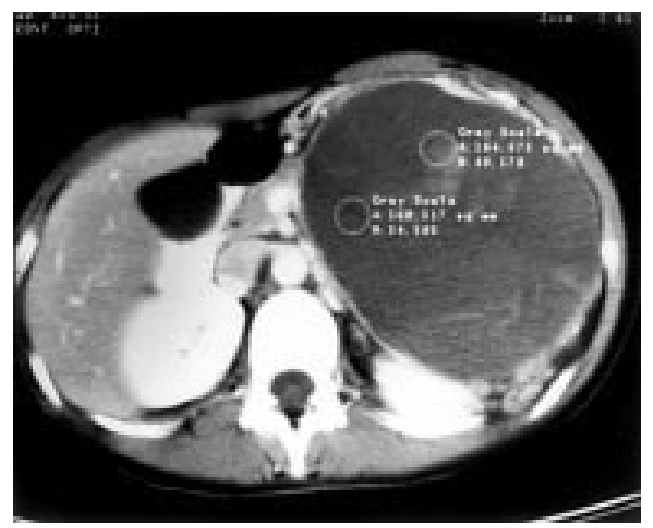

Figure 1 Axial computed tomography scan of the upper abdomen shows a circumscribed tumour in the transverse mesocolon, which dislocates but does not infiltrate the surrounding organs. 
labelled; Oncor) gene status of the tumour cells. D17Z1 (cen.17, digoxigenin labelled; Oncor) and D13S327 (13q34-qter, digoxigenin labelled; Oncor) probes were cohybridised with the p53 and RB1 probes, respectively. The biotin labelled probes were detected by means of avidin-fluorescein isothiocyanate (FITC; Vector, Burlingame, California, USA), the digoxygenin labelled ones by means of the anti-digoxygenin-rhodamine (Boehringer, Mannheim, Germany) system, resulting in green and red fluorescence, respectively. CGH was used to define the possible gain and/or loss of genetic material. For DNA extraction, the "salting out" method described by Miller et al was used. ${ }^{8} \mathrm{CGH}$ was performed according to the protocol used by du Manoir et al. ${ }^{9}$

Histologically, the tumour had a fibrous pseudocapsule with ectopic, compressed pancreatic tissue around and in it (fig 2A).
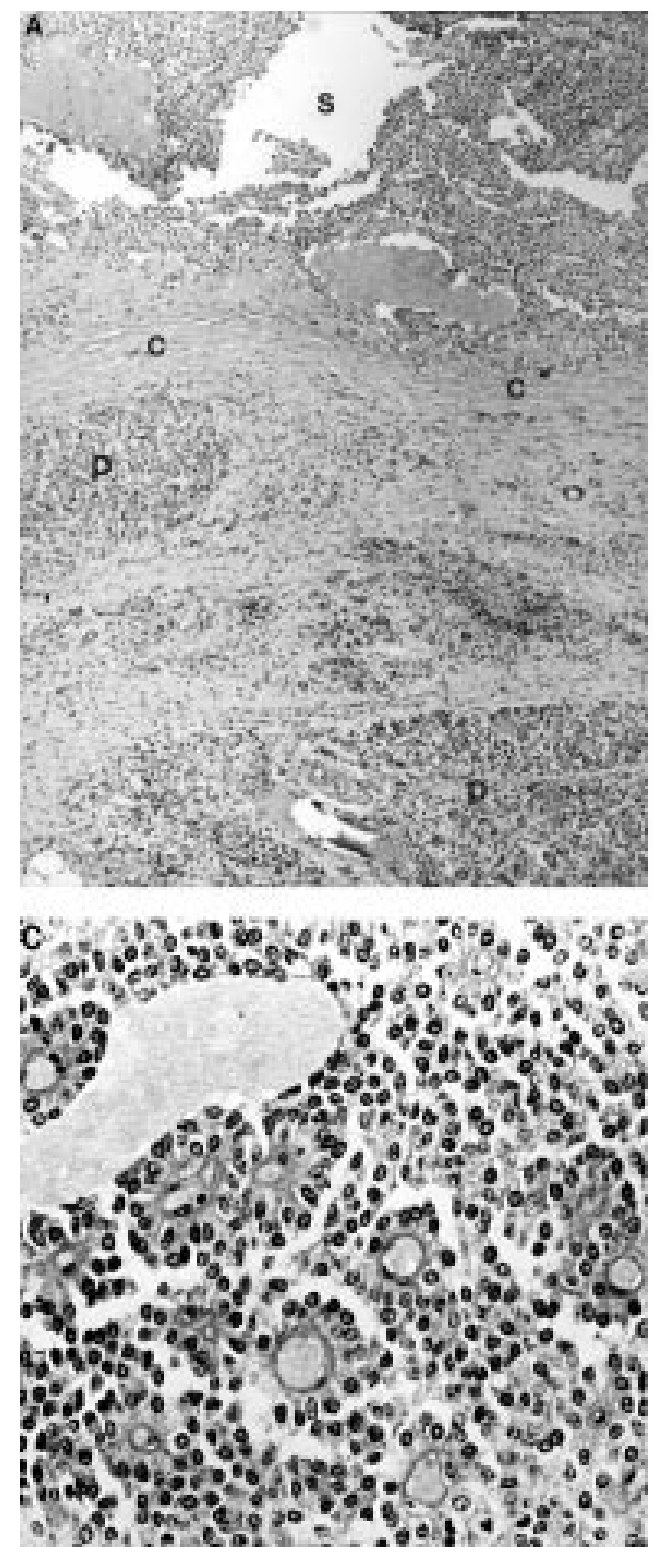

Because of the widespread necrosis and haemorrhage, only the peripheral parts of the tumour were suitable for histological evaluation. The neoplasm consisted of small, rather uniform, round to polygonal cells with eccentrically placed nuclei containing single small nucleoli. The cytoplasm was pale eosinophilic with slight granularity. The tumour cells were arranged in solid sheets or pseudopapillary structures. In the latter, the cells had a columnar appearance pallisading around a central vascular core (fig $2 \mathrm{~B}$ and $\mathrm{C}$ ). In the solid areas, numerous cholesterol granulomata and sheets of foamy macrophages were present. The tumour was richly vascularised and contained thin walled blood vessels. In some cell clusters, the periodic acid Schiff (PAS) staining revealed dot-like positivity. Immunohistochemically, the cells showed strong, focal cytoplasmic positivity for vimentin, KL-1, neurone
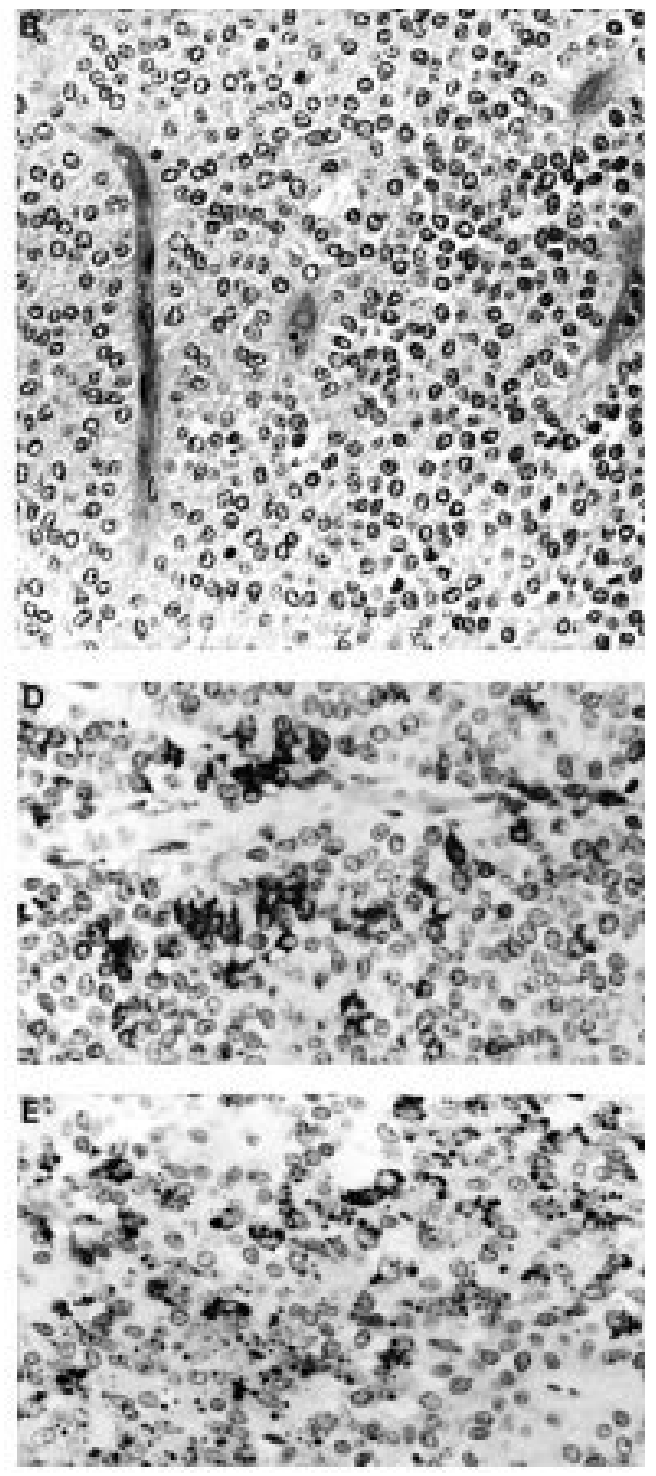

Figure 2 (A) Low power photomicrograph of the tumour $(S)$ showing the fibrous pseudocapsule $(C)$ and the ectopic pancreatic tissue $(P)$. Tumour cells are arranged in $(B)$ solid sheets or $(C)$ form pseudopapillary structures around the blood vessels. Two characteristic immunophenotypic features were: (D) the strong, focal KL-1 positivity, and (E) the focal, granular or dot-like a-1-antichymotrypsin positivity. 
specific enolase (NSE), and intracytoplasmic carcinoembryonic antigen (CEA), and focal, granular cytoplasmic positivity for

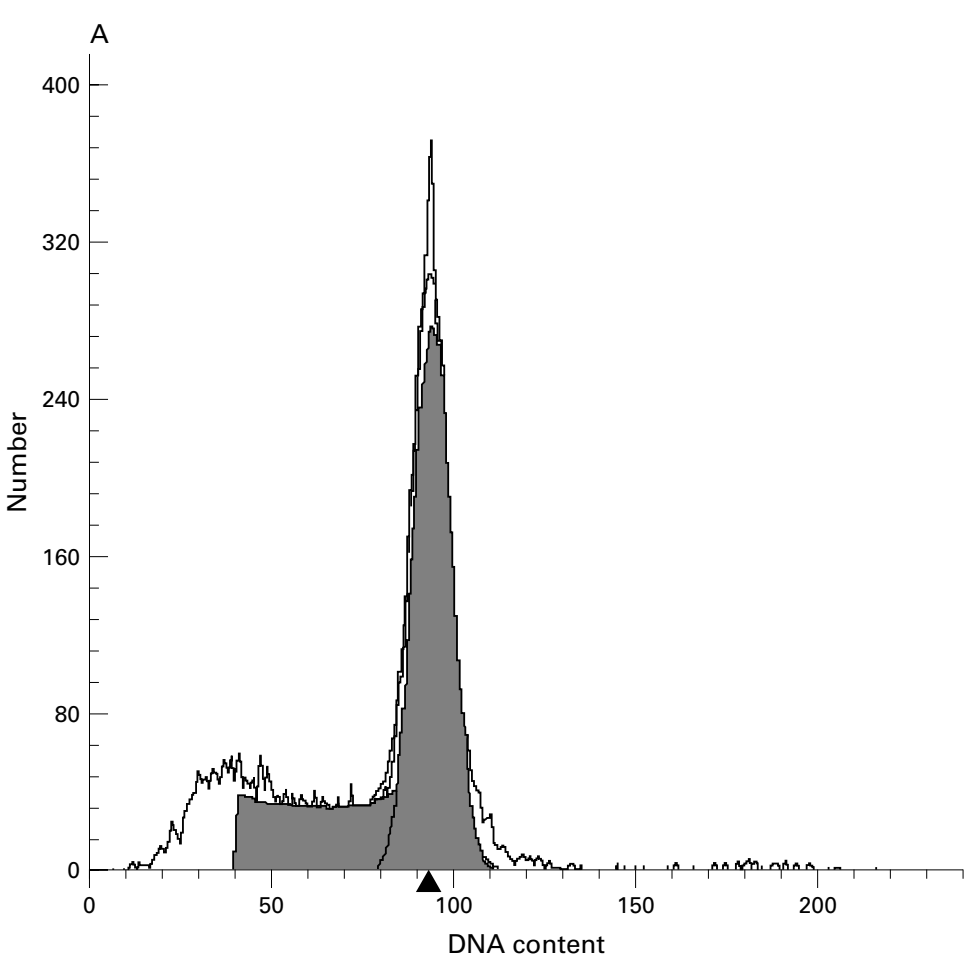

B
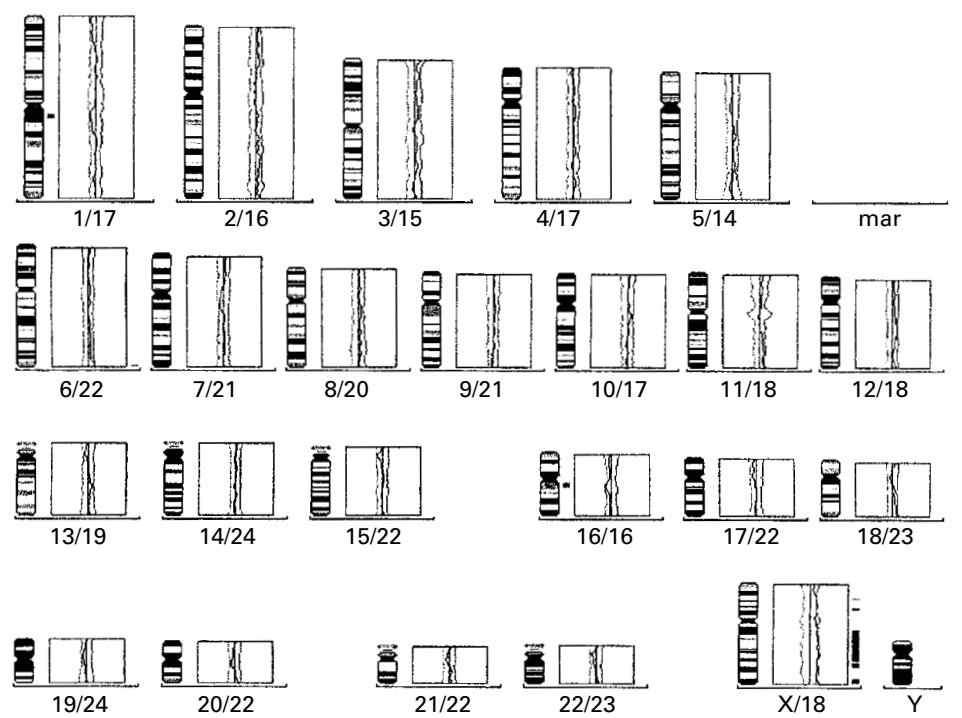

Figure 3 (A) Characteristic single diploid peak on the histogram. (B) Comparative genomic hybridisation shows no gain or loss in the genetic material.

Table 1 Summary of the present and previously published cases

\begin{tabular}{|c|c|c|c|c|c|}
\hline & Age/sex & Size (cm) & Site & $\begin{array}{l}\text { Heterotopic } \\
\text { pancreas }\end{array}$ & Symptoms \\
\hline Case $1^{2}$ & $13 / \mathrm{F}$ & 8 & Mesocolon & Yes & Pain \\
\hline Case $2^{4}$ & $17 / \mathrm{F}$ & 7 & Omentum & Yes & Mass \\
\hline Case $3^{1}$ & $33 / \mathrm{F}$ & 6 & Mesocolon & Yes & Mass \\
\hline Case $4^{3}$ & $41 / \mathrm{F}$ & 7.5 and 5.5 & Liver & No data & Distension \\
\hline Case $5^{5}$ & $25 / M$ & 8 & Mesocolon $\star$ & Yes $\star \star$ & None \\
\hline Present case & $15 / \mathrm{F}$ & 21 & Mesocolon & Yes & Pain \\
\hline
\end{tabular}

${ }^{\star}$ In case 5 the tumour was located beneath the mesocolon transversum.

${ }^{\star \star}$ In case 5 only pancreatic ducts could be found in the capsule.

Numbers in superscript are the original references.

F, female; $M$, male. $\alpha 1$-antitrypsin $\quad(\alpha 1 \mathrm{AT}) \quad$ and $\quad \alpha 1-$ antichymotrypsin ( $\alpha 1 \mathrm{ACT}$ ) (fig $2 \mathrm{D}$ and $\mathrm{E}$ ). All the other markers, including EMA, BerEP4, desmin, leucocyte common antigen (LCA), glial fibrillar acidic protein (GFAP), the oestrogen receptor (ER), the progesterone receptor (PR), p53, cytokeratin (CK), and the neuroendocrine markers such as chromogranin-A, synaptophysin, neurofilament (NF), S100, and PGP9.5 were negative. No mitoses were found, and the Mib1 (Ki67) antibody showed nuclear staining in about $1 \%$ of the tumour cells at the viable periphery of the neoplasm. In spite of the signs of necrosis, mitochondria, desmosomes, rough endoplasmic reticulum fragments, Golgi apparatus, and scant zymogen granules with finely granular matrix and eccentric dense bodies could be identified on electron microscopic examination. No neurosecretory granules could be detected.

On the flow cytometric histogram a single diploid peak was seen with a low, 3.25\% S-phase fraction and $96 \%$ G0-G1 cells at CV: 5.31 (fig 3A).

In situ hybridisation analysis of the $13 \mathrm{q}$ and the $17 p$ arms, by means of the RB1/D13S327 and TP53/D17Z1 probes, respectively, gave two red and two green signals in both cases, ruling out loss or gain at the investigated regions. The results indicate structurally normal 13q and 17p chromosome arms. CGH did not reveal gain or loss in the genetic material of the tumour (fig 3B), which is in agreement with the flow cytometry finding of diploidy.

SPEN constitutes less than $1 \%$ of all pancreatic tumours. It can occur in any part of the gland, more frequently in the tail and the head. The occurrence of SPEN outside the pancreas is still regarded as a curiosity and only five previously published cases have been identified (table 1). Although it is sometimes difficult to make a diagnosis of SPEN in the pancreas, it becomes a diagnostic challenge when it occurs elsewhere. The presence of ectopic pancreatic tissue, as seen in three of the five previously published cases, is an important clue to the diagnosis. Barbosa de Castro et al studied the distribution of ectopic pancreatic tissue in 471 necropsies and reported only $0.4 \%$ in the mesocolon. ${ }^{10}$ In contrast, four of the six tumours reviewed here were localised to the mesocolon (or just beneath the transverse mesocolon in case 5). These six tumours (table 1 ) tended to grow to a large size (60-210 mm), usually occurred in young female patients (only one was in a man), and produced similar clinical signs. In all five published cases the tumour was found to be separate from the main pancreas at surgery. All had a pseudocapsule and in four of the specimens (not cases 4 and 5) heterotopic, compressed pancreatic tissue was present at the periphery. In case 5, only ductular structures resembling pancreatic ducts were found. ${ }^{5}$ In case 4 , the neoplasm developed in the liver, but the presence of pancreatic tissue in or around the tumour was not mentioned. ${ }^{3}$ The fact that SPEN developed in the liver raises the possibility of the presence of 
pluripotent, primordial "pancreatic" cells in this organ, which seems to be supported by the common development of both pancreas and liver from the primitive duodenum.

The histological pattern of SPEN is very characteristic, as is the cytological appearance. ${ }^{11-13}$ Some of the reports emphasise the value and role of fine needle aspiration biopsy (FNAB), which gives preoperative diagnosis and helps in planning surgical intervention by distinguishing SPEN from other, more aggressive neoplasms. ${ }^{112}$ In contrast, the immunophenotype of the tumour cells is inconsistent in the different publications. ${ }^{14}$ The most frequently positive markers are $\alpha 1 \mathrm{AT}$, $\alpha 1 \mathrm{ACT}, \mathrm{NSE}$, vimentin, and broad spectrum cytokeratin, as was found in our case. ${ }^{515-18}$ However, apart from these markers, strong intracytoplasmic CEA positivity was also noted, which is in contrast to the negative results reported by many authors. ${ }^{18}$ Negativity with the known neuroendocrine markers such as NF, chromogranin, synaptophysin, PGP9.5, and $\mathrm{S} 100$ does not support a neuroendocrine origin or differentiation. The striking female predominance provoked immunohistochemical studies for oestrogen and progesterone receptors that led to controversial results. Some authors found the neoplasm negative for oestrogen and positive for progesterone receptors ${ }^{19}$; however, in other publications, several cases proved to be negative for both hormone receptors. ${ }^{517}{ }^{18}$ Complicating the issue, oestrogen receptor positive SPEN has also been described. ${ }^{10}$ The tumour in our case failed to react with any of the above antibodies for hormone receptors. This is probably a true result and not the result of widespread tumour necrosis because other antibodies worked well on the same preparation. The p53 negativity indicates no overexpression, which is in agreement with the ISH findings.

On ultrastructural studies, some authors found zymogen-like and/or neurosecretory granules (exocrine and/or endocrine features) in the tumour cells; however, others saw no definitive evidence of such a differentiation. ${ }^{17} 182021$ These findings might indicate a pluripotent pancreatic cell origin, where the tumour cells may express markers characteristic of both cell lineages. ${ }^{1622}$ Our electron microscopic findings may support exocrine cell differentiation.

All but two of the published SPENs proved to be diploid with a low S-phase fraction in flow cytometric studies. ${ }^{13}{ }^{17}$ Our case also showed diploidy with a low S-phase fraction (3.25\%), which correlated well with the low proliferative activity (low number of Mib1 positive cells and virtual absence of mitotic figures) and indolent behaviour of the tumour.

Considerably much less is known about the molecular pathological background. Grant et al pointed to an unbalanced chromosomal translocation - der $(17) \mathrm{t}(13 ; 17)(\mathrm{q} 14 ; \mathrm{p} 11)-$ found in a pancreatic $\mathrm{SPEN}^{7}$; however, in our case, the p53 and the RB1 genes seemed to be intact in these regions and no gain or loss could be demonstrated on the $13 \mathrm{q}$ and the $17 \mathrm{p}$ chromosome arms. The translocation described ${ }^{7}$ was restricted to a minor subpopulation of cells (five of the 20 mitoses) and might be related to the transformation and not to a basic genetic alteration of the tumour. In agreement with our flow cytometric and ISH data, the CGH did not show quantitative changes in the genetic material (fig 3B). Bartsch et al emphasised the absence of K-ras mutations in these tumours in contrast to other cystic malignant pancreatic neoplasms, where an association between mutation and malignant behaviour was clearly demonstrated. ${ }^{6}$ The similar and unique macroscopic and microscopic morphology, clinical presentation, and biological behaviour of these tumours suggest a common, discrete genetic abnormality that remains unclear. This does not cause detectable gain or loss in the genetic material as shown by the investigations carried out.

The clinical course of SPEN is usually favourable; only forty three $(14.7 \%)$ cases behaved in a malignant fashion. However, because this tumour (although rarely) can have metastatic potential and may recur, wide and complete surgical resection is recommended and regular clinical ultrasonographic investigations must be carried out. ${ }^{23}$ The histological features of SPEN are sufficiently distinctive to be recognised even at a heterotopic site.

The authors thank V Kalász for technical assistance, and Dr C Stock (CCRI, St Anna Children's Hospital, Vienna) for performing the CGH reaction.

1 Elorza Oure JL, Ruiz Diaz I, Tubia-Landaberea J, et al. Solid and papillary tumour on ectopic pancreas in transversal mesocolon. Rev Esp Enferm Dig 1991;79:429-31.

2 Ishikawa $\mathrm{O}$, Ishiguro $\mathrm{S}$, Ohhigashi $\mathrm{H}$, et al. Solid and papillary neoplasm arising from an ectopic pancreas in the mesocolon. Am f Gastroenterol 1990;85:597-600.

3 Kim IK, Kim ST, Lee GK, et al. Papillary cystic tumour of the liver. A case report with ultrastructural observation. Cancer 1990;65:2740-6.

4 Kôvári E, Járay B, Pulay I. Papillary and cystic neoplasm on ectopic pancreas. Orv Hetil 1996;137:923-5.

5 Klöppel G, Maurer R, Hofmann E, et al. Solid-cystic (papillary-cystic) tumours within and outside the pancreas in men: report of two patients. Virchows Arch A Pathol Anat in men: report of two patients.

6 Bartsch D, Bastian D, Barth P, et al. K-ras oncogene mutations indicate malignancy in cystic tumours of the pancreas. Ann Surg 1998;228:79-83.

7 Grant LD, Lauwers GY, Meloni AM, et al. Unbalanced chromosomal translocation $\operatorname{der}(17) \mathrm{t}(13 ; 17)(\mathrm{q} 14 ; \mathrm{p} 11)$ in a solid and cystic papillary epithelial neoplasm of the pancreas. Am f Surg Pathol 1996;20:339-45.

8 Miller SA, Dykes DD, Polesky HF. A simple salting out procedure for extracting DNA from human nucleated cells. Nucleic Acids Res 1988;16:1215.

9 du Manoir S, Speicher MR, Joos S, et al. Detection of complete and partial chromosome gains and losses by comparative genomic in situ hybridisation. Hum Genet 1993;90:590-610

10 Barbosa De Castro J, Dockerty MB, Waugh JM. Pancreatic heterotopia. Surg Gynecol Obstet 1946;82:527-42.

11 Kashima K, Hayashida Y, Yokohama J, et al. Cytologic features of solid and cystic tumour of the pancreas. Acta Cytol 997;41:443-9.

12 Pelosi G, Iannucci A, Zamboni G, et al. Solid and cystic papillary neoplasm of the pancreas: a clinicocytopathologic and immunocytochemical study of five new cases diagnosed by fine needle aspiration cytology and a review of the literature. Diagn Cytopathol 1995;13:233-46.

13 Wilson MB, Adams DB, Garen PD, et al. Aspiration cytologic, ultrastructural, and DNA cytometric findings of solid and papillary tumour of the pancreas. Cancer 1992;69:2235-43.

14 Lack EE. Primary tumours of the exocrine pancreas. Classification, overview, and recent contributions by immunohistochemistry and electron microscopy. Am f Surg Pathol tochemistry and electron

15 Learmonth GM, Price SK, Visser AE, et al. Papillary and cystic neoplasm of the pancreas - an acinar cell tumour? Histopathology 1985;9:63-79. 
16 Matsunou H, Konoshi F. Papillary-cystic neoplasm of the pancreas. A clinicopathologic study concerning the tumour ageing and malignancy of nine cases. Cancer 1990;65:283-

17 Pettinato G, Manivel JC, Ravetto C, et al. Papillary cystic tumour of the pancreas. A clinicopathologic study of 20 cases with cytologic, immunohistochemical, ultrastructural, and flow cytometric observations, and review of the literature. Am f Clin Pathol 1992;98:478-88.

18 Stömmer P, Kraus J, Stolte M, et al. Solid and cystic pancreatic tumours. Clinical, histochemical, and electron microscopic features in ten cases. Cancer 1991;67:1635-41.

19 Zamboni G, Bonetti F, Scarpa A, et al. Expression of progesterone receptors in solid-cystic tumour of the pancreas: a clinicopathological and immunohistochemical study of ten cases. Virchows Arch A Pathol Anat Histopathol 1993;423:425-31.

20 Miettinen M, Partanen S, Fraki O. Papillary cystic tumour of the pancreas: an analysis of cellular differentiation by electron microscopy and immunohistochemistry. $A m \mathcal{F}$ Surg Pathol 1987;11:855-66.

21 de la Roza G, Cleary KR, Ordonez NG, et al. Solid and papillary tumour of the pancreas: ultrastructural observations on two contrasting cases. Ultrastruct Pathol 1997;21:439-47.

22 Balercia G, Zamboni G, Bogina G, et al. Solid-cystic tumour of the pancreas. An extensive ultrastructural study of fourteen cases. I Submicrosc Cytol Pathol 1995;27:331-40.

23 Matsunou $\mathrm{H}$, Konishi $\mathrm{F}$, Yamamichi $\mathrm{N}$, et al. Solid, infiltrating variety of papillary cystic neoplasm of the pancreas. Cancer 1990;65:2747-57.

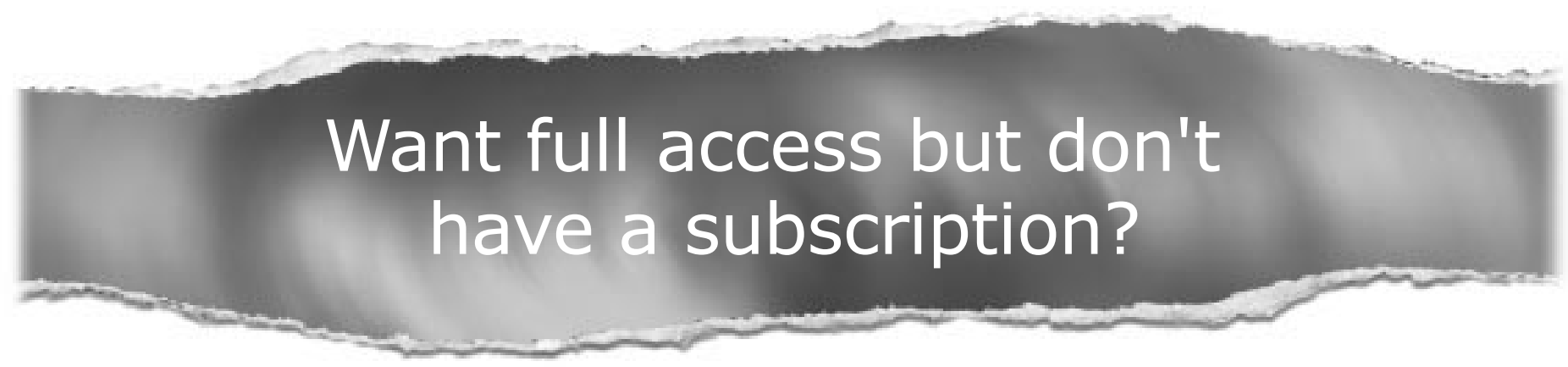

Pay per access

For just US\$25 you can have instant access to the whole website for 30 days. During this time you will be able to access the full text for all issues (including supplements) available. You will also be able to download and print any relevant pdf files for personal use, and take advantage of all the special features Journal of Clinical Pathology online has to offer.

\section{www.jclinpath.com}

